\title{
CARACTERÍSTICAS QUALITATIVAS DA PASTAGEM DE AVEIA PRETA E AZEVÉM MANEJADA SOB DIFERENTES ALTURAS, OBTIDA POR SIMULAÇÃO DE PASTEJO
}

\section{Quality of black oat and ryegrass submitted to different heights of grazing collected by hand-plucking}

\author{
PIAZZETTA, R.G. ${ }^{1}$; DITTRICH, J.R. ${ }^{2}$; ALVES, S.J. ${ }^{3}$; MORAES, A. ${ }^{4}$; LUSTOSA, S.B.C. ${ }^{5}$; \\ GAZDA, T.L. ${ }^{6}$; MELO, H.A. ${ }^{6}$; MONTEIRO, A.L.G. ${ }^{2}$
}

${ }^{1}$ Médico Veterinário, MSc. - Ministério da Agricultura Pecuária e Abastecimento

2 Departamento de Zootecnia - UFPR

3 Eng ${ }^{\circ}$ Agrônomo - IAPAR

${ }^{4}$ Departamento de Fitotecnia e Fitossanitarismo - UFPR

${ }^{5}$ Engo ${ }^{\circ}$ Agrônomo - UNICENTRO

${ }^{6}$ Médica Veterinária - UFPR

Endereço para correspondência: Ricardo Guimarães Piazetta: ricardo_pzt@hotmail.com

\section{RESUMO}

O objetivo desse experimento foi avaliar o valor bromatológico da pastagem de aveia preta e azevém submetida a diferentes alturas de pastejo, obtida pela simulação de pastejo. O experimento foi conduzido na Fazenda Experimental da COAMO, Campo Mourão/PR. O delineamento experimental adotado foi de blocos ao acaso, com quatro tratamentos e duas repetições. Os tratamentos foram constituídos por diferentes alturas da pastagem: $7 \mathrm{~cm}$ de altura; $14 \mathrm{~cm}$ de altura; $21 \mathrm{~cm}$ de altura e $28 \mathrm{~cm}$ de altura. $O$ método de amostragem utilizado foi a simulação manual do pastejo. Os valores médios de proteína bruta foram de $23,8 \% ; 21,8 \% ; 20,8 \%$ e $20,9 \%$ para os tratamentos de $7 \mathrm{~cm} ; 14 \mathrm{~cm} ; 21 \mathrm{~cm}$ e $28 \mathrm{~cm}$ respectivamente. A análise de regressão demonstra que houve resposta quadrática da altura da pastagem sobre os teores médios de proteína bruta. Os valores médios de fibra em detergente ácido (FDA) foram de 25,5\%; $28,0 \%$; $27,2 \%$ e $26,0 \%$ para os tratamentos de $7 \mathrm{~cm} ; 14 \mathrm{~cm} ; 21 \mathrm{~cm}$ e $28 \mathrm{~cm}$ respectivamente. E os valores de fibra em detergente neutro (FDN) foram de $58,5 \% ; 62,2 \% ; 59,7 \%$ e $60,5 \%$ para os tratamentos de $7 \mathrm{~cm} ; 14 \mathrm{~cm}$; $21 \mathrm{~cm}$ e $28 \mathrm{~cm}$ respectivamente. Os valores médios de fibra em detergente ácido (FDA) e fibra em detergente neutro (FDN) não apresentaram diferença entre as alturas de pastejo. A utilização da pastagem de aveia preta e azevém em menor altura implicou no aumento dos teores de proteína bruta da forragem obtida na simulação de pastejo dos animais.

Palavras-chave: FDA, FDN, proteína bruta.

\begin{abstract}
This trial aimed to evaluate the nutritive value of black oat and ryegrass pasture submitted to different heights of grazing. The study was carried out in Experimental Farm from Cooperativa Agropecuaria Mourãoense - COAMO in Campo Mourão city, Paraná State, Brazil. Experimental area corresponded to 8 ha, with randomized blocks design, with four treatments, which corresponded to four heights of pasture: 7 , $14,21,28 \mathrm{~cm}$ and two replications. Samples were collected by hand-plucking. Average values of crude protein were $23,8 \% ; 21,8 \% ; 20,8 \%$ and $20,9 \%$ for $7 ; 14 ; 21$ and $28 \mathrm{~cm}$, respectively. The crude protein contents presented quadratic response to height of pasture. Quantities of acid detergent fiber (ADF) were $25,5 \% ; 28,0 \% ; 27,2 \%$ e $26,0 \%$ for $7 ; 14 ; 21$ and $28 \mathrm{~cm}$, respectively. Values of neutral detergent fiber (NDF) were $58,5 \% ; 62,2 \% ; 59,7 \%$ e $60,5 \%$ for $7 ; 14 ; 21$ and $28 \mathrm{~cm}$ treatments, respectively. The quantity of ADF and NDF did not show statistic difference between heights of grazing.
\end{abstract}

Key words: ADF, crude protein, NDF 


\section{INTRODUÇÃO}

O principal fator responsável pelas baixas produtividades na pecuária é a falta de alimentação constante nas diferentes épocas do ano, uma vez que a produção de forragem ocorre de modo estacional, com grande produção forrageira no período de primavera e verão, e baixa produção nos meses de outono e inverno. Em razão disso, entre os meses de maio a outubro, os animais não conseguem consumir forragens em quantidade e qualidade suficientes para atender suas necessidades nutricionais, o que ocasiona perda de peso (Bona Filho e Martinichen, 2002).

A região sul do Brasil apresenta clima favorável ao estabelecimento de espécies forrageiras de clima temperado. Estas, por sua vez, apresentam seu desenvolvimento justamente no período crítico para produção de pastagens de clima tropical. Portanto, o uso de forrageiras anuais de estação fria constitui importante alternativa para produção animal (Roso e Restle, 2000).

As espécies anuais de inverno mais utilizadas para pastejo são aveia preta (Avena Strigosa Schreb) e azevém (Lolium multiflorium Lam), isoladas ou em misturas, basicamente em função da facilidade na aquisição de sementes e das particularidades em relação ao ciclo de produção das espécies (Roso et al., 2000).

As regiões Oeste e Centro Ocidental do Estado do Paraná apresentam clima Cfa, no qual a ocorrência de chuvas nos meses do inverno é menor. Salienta-se então a necessidade de se avaliar o desenvolvimento de espécies forrageiras de clima temperado nesta região.

Pesquisas com bovinos em pastejo têm sido realizadas para o aperfeiçoamento da determinação da qualidade da forragem ingerida pelos animais nestas condições. A coleta de amostras com base na disponibilidade total não representa a dieta selecionada pelo animal, pois superestima o conteúdo fibroso e subestima os teores de proteína bruta do pasto (Goes et al, 2003; Moraes et al, 2005). Estudos demonstraram que a metodologia da simulação manual de pastejo possibilita uma estimativa aceitável da forragem selecionada por animais em regime de pastejo (Moraes et al, 2005), o que possibilita indicar como um método viável por sua representabilidade e praticidade (Goes et al, 2003).

Diante do exposto, o objetivo desse experimento foi avaliar 0 valor bromatológico da pastagem de aveia preta e azevém submetida a diferentes alturas de pastejo, obtida pela simulação de pastejo de novilhas de corte, na região de Campo Mourão/PR.

\section{MATERIAL E MÉTODOS}

O experimento foi conduzido em área da Fazenda Experimental da Cooperativa Agropecuária Mourãoense - COAMO, situada no município de Campo Mourão, Paraná. O clima da região é descrito como Cfa, segundo classificação de Köeppen (Moreno, 1961).

A área experimental vinha sendo cultivada há cinco anos no sistema de integração lavoura-pecuária, com o cultivo de soja e milho no verão e pastagens de aveia e azevém durante o inverno.

O delineamento experimental adotado foi de blocos ao acaso, com quatro tratamentos e duas repetições. A área experimental constituiu-se de oito hectares, divididos em oito piquetes. Os tratamentos foram constituídos por diferentes alturas de pastejo: $7 \mathrm{~cm}$; $14 \mathrm{~cm}$; $21 \mathrm{~cm}$ e $28 \mathrm{~cm}$. As alturas reais obtidas durante o experimento foram: $7,8 \mathrm{~cm} ; 13,8 \mathrm{~cm} ; 20,5 \mathrm{~cm}$ e $28,4 \mathrm{~cm}$. Como as alturas obtidas ficaram muito próximas das alturas desejadas, para efeito da apresentação e discussão dos resultados estarão sendo empregados de forma padronizada os valores de altura inicialmente pretendidos. 
A pastagem de aveia e azevém foi implantada em abril de 2005, por meio de plantio direto sobre a palha da soja, com espaçamento entre linhas de $16 \mathrm{~cm}$ e densidade de semeadura de $60 \mathrm{~kg} / \mathrm{ha}$ de aveia preta cultivar IAPAR 61 (Avena strigosa Schreb.) e $30 \mathrm{~kg} / \mathrm{ha}$ de azevém comum (Lolium multiflorum Lam.).

O solo da área do experimento apresentava $\mathrm{pH}$ em água de 6,$0 ; 4,78$ cmolc de $\mathrm{H}^{+}+\mathrm{Al}^{+3} / \mathrm{dm}^{3}$ de solo; 4,57 cmolc $/ \mathrm{dm}^{3}$ de $\mathrm{Ca}^{+2}, 1,45 \mathrm{cmolc} / \mathrm{dm}^{3}$ de $\mathrm{Mg}^{+2} ; 0,27 \mathrm{cmolc} / \mathrm{dm}^{3}$ de $\mathrm{K}+; 2,78 \mathrm{mg} / \mathrm{dm}^{3}$ de $\mathrm{P} ; 17,53 \mathrm{~g} / \mathrm{dm}^{3}$ de $\mathrm{C} ; 7,00 \%$ de areia grossa; $16,00 \%$ de areia fina; $3,00 \%$ de silte e $74,00 \%$ de argila.

A adubação de base foi realizada com foi de $16 \mathrm{~kg}$ de N/ha, $32 \mathrm{~kg}$ de $\mathrm{P} 2 \mathrm{O} 5 / \mathrm{ha}$ e $32 \mathrm{~kg}$ de $\mathrm{K} 2 \mathrm{O} / \mathrm{ha}$ (200 kg/ha de 8-16-16). A adubação nitrogenada de cobertura realizada foi de $150 \mathrm{~kg}$ de N/ha, na forma de uréia $(45 \%$ de $N)$, dividida em duas etapas: $75 \mathrm{~kg}$ de N/ha no mês de maio e 75 $\mathrm{kg}$ de N/ha em julho.

Foram utilizadas 16 novilhas testes e 16 novilhas reguladoras, resultantes do cruzamento das raças Nelore e Red Angus, com peso médio inicial de $200 \mathrm{~kg}$ e idade de 10 a 12 meses.

O método de pastejo foi o contínuo com taxa de lotação variável, conforme metodologia proposta por Mott e Lucas (1952). Para cada unidade experimental foram utilizados dois animais testes e um número variável de reguladores conforme a altura pretendida. $\mathrm{O}$ acompanhamento das alturas foi realizado semanalmente, por meio da aferição da altura em 50 pontos em cada unidade experimental, utilizandose o Sward Stick (Barthram, 1986). A altura média da pastagem dos piquetes foi obtida pelo somatório das avaliações semanais, divididas pelo número de avaliações e expressa em centímetros.

O método de amostragem utilizado foi a simulação manual do pastejo (SMP) conforme Johnson (1978), identificando-se o tipo de material consumido e coletandose uma amostra semelhante ao alimento ingerido. A coleta foi realizada por um único amostrador em todo o período experimental, a fim de se evitar variações em cada amostragem.

Para cada data avaliada foram coletadas duas amostras por área experimental, totalizando quatro amostras por tratamento.

Após as coletas, as amostras foram encaminhadas para 0 Laboratório de Nutrição Animal da Universidade Federal do Paraná (UFPR), no qual se realizou a pré-secagem em estufa a $65^{\circ} \mathrm{C}$, por 72 horas, sendo posteriormente processadas em moinho com peneira de $1 \mathrm{~mm}$.

A análise bromatológica para a obtenção dos teores de Proteína Bruta (PB) foi realizada pelo método de Kjeldahl (AOAC, 1997). Os níveis de Fibra em Detergente Neutro (FDN) e Fibra em Detergente Ácido (FDA) foram obtidos pelo método de Van Soest et al. (1991).

As variáveis estudadas foram submetidas à análise de variância e as médias comparadas pelo teste $\mathrm{F}$ ao nível de $5 \%$ de significância, bem como pela regressão. As análises foram realizadas utilizando-se o programa estatístico SISVAR (Ferreira, 2003).

\section{RESULTADOS E DISCUSSÃO}

Os valores encontrados para proteína bruta (PB), fibra em detergente ácido (FDA) e fibra em detergente neutro (FDN) das amostras obtidas pelo método de simulação de pastejo estão apresentados na Tabela 1.

As diferentes alturas de pastejo interferiram nos valores médios de proteína bruta das amostras obtidas pelo método de simulação de pastejo. Os tratamentos de $21 \mathrm{~cm}$ e $28 \mathrm{~cm}$ apresentaram valores médios inferiores $(P<0,05)$ de proteína bruta em relação ao tratamento de $7 \mathrm{~cm}$ de altura.

A análise de regressão demonstra que houve resposta quadrática da altura da pastagem sobre os teores médios de 
Tabela 1 -Teores de proteína bruta (PB), fibra em detergente ácido (FDA) e fibra em detergente neutro (FDN) nas diferentes alturas da pastagem de aveia e azevém

\begin{tabular}{|c|c|c|c|c|c|c|}
\hline \multirow{2}{*}{ Tratamento $(\mathrm{cm})$} & $30 / 06 / 05$ & $28 / 07 / 05$ & $17 / 08 / 05$ & $28 / 09 / 05$ & $17 / 10 / 05$ & Média \\
\hline & \multicolumn{6}{|c|}{ Proteína Bruta (\%) } \\
\hline 7 & 26,17 & 27,54 & 25,15 & 21,45 & 18,72 & 23,80 \\
\hline 14 & 22,22 & 25,14 & 24,45 & 19,69 & 17,52 & 21,80 \\
\hline 21 & 26,19 & 23,19 & 21,63 & 17,31 & 15,70 & 20,80 \\
\hline 28 & 27,94 & 22,83 & 20,86 & 16,76 & 16,23 & 20,92 \\
\hline Média & 25,63 & 24,67 & 23,02 & 18,80 & 17,04 & \\
\hline \multicolumn{7}{|l|}{$\mathrm{CV}(\%)=8,73$} \\
\hline & \multicolumn{6}{|c|}{ Fibra em Detergente Ácido - FDA (\%) } \\
\hline 7 & 24,79 & 21,67 & 25,45 & 26,66 & 29,27 & 25,57 \\
\hline 14 & 31,33 & 24,89 & 25,78 & 27,20 & 30,86 & 28,01 \\
\hline 21 & 24,43 & 25,37 & 24,79 & 28,19 & 33,26 & 27,21 \\
\hline 28 & 22,59 & 27,89 & 26,59 & 26,13 & 26,86 & 26,01 \\
\hline Média & 25,78 & 24,95 & 25,65 & 27,04 & 30,06 & \\
\hline \multicolumn{7}{|l|}{$\mathrm{CV}(\%)=9,85$} \\
\hline & \multicolumn{6}{|c|}{ Fibra em Detergente Neutro - FDN (\%) } \\
\hline 7 & 59,26 & 59,27 & 58,33 & 57,62 & 58,07 & 58,51 \\
\hline 14 & 66,33 & 62,93 & 57,86 & 58,15 & 65,83 & 62,22 \\
\hline 21 & 52,65 & 62,63 & 57,84 & 60,12 & 65,50 & 59,75 \\
\hline 28 & 58,77 & 65,92 & 58,67 & 59,94 & 59,11 & 60,48 \\
\hline Média & 59,25 & 62,69 & 58,17 & 58,95 & 62,13 & \\
\hline $\mathrm{CV}(\%)=2,74$ & & & & & & \\
\hline
\end{tabular}

proteína bruta (Figura 1), sendo que o aumento da altura da pastagem ocasionou a diminuição nos valores médios de proteína bruta. Esse resultado difere do obtido por Freitas et al. (2003) que não observou diferença nos valores de proteína bruta em azevém pastejado por ovinos em três alturas diferentes. Outros autores analisando o valor bromatológico de pastagens de aveia e azevém submetidas a diferentes ofertas de pastejo também não observaram diferença nos valores de proteína bruta da pastagem (Gazda et al., 2004; Piazzetta et al., 2004).

Porém, segundo Barbosa et al. (2007) pastagens com maior intensidade de pastejo apresentam melhor qualidade, pois o crescimento da pastagem é constante, com maior presença de material vegetativo mais tenro, com perfilhos e folhas jovens, o que corrobora com os dados obtidos para PB no presente trabalho.

O NRC (1984) estabelece o valor de $129 \mathrm{~g}$ de $\mathrm{PB} / \mathrm{kg}$ de MS para recria de novilhas de corte. Os valores de PB obtidos no trabalho variaram de 157 a 279 $\mathrm{g} / \mathrm{kg}$ de MS, portanto o teor de PB da pastagem de aveia e azevém permite expressar, para esta categoria, o máximo ganho de peso.

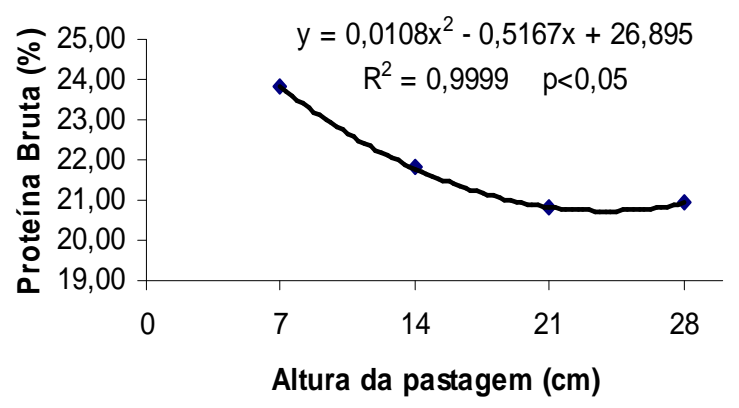

Figura 1 - Valores médios de proteína bruta (\%) da pastagem de aveia preta e azevém submetida a quatro alturas de manejo.

Com relação aos valores de proteína bruta para o cultivar de aveia preta IAPAR 61, utilizado nesse experimento, os dados de literatura variam de $16 \%$ a $21 \%$ (Cecato et al., 1998; Macari et al., 2006). 
A)

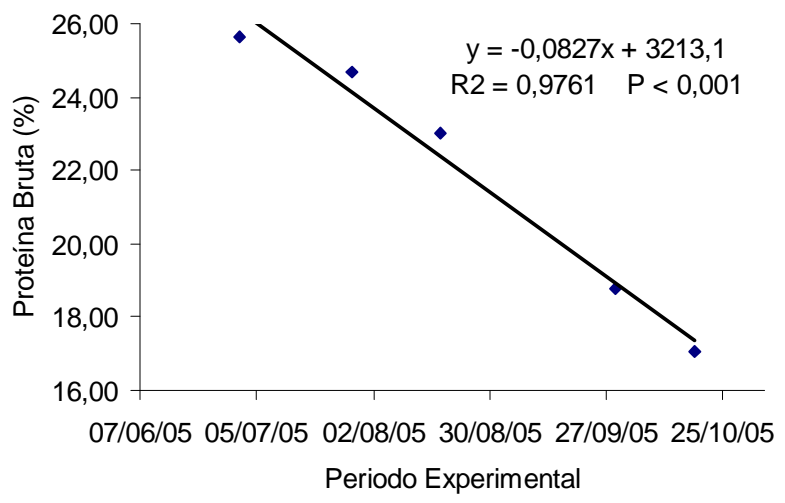

B)

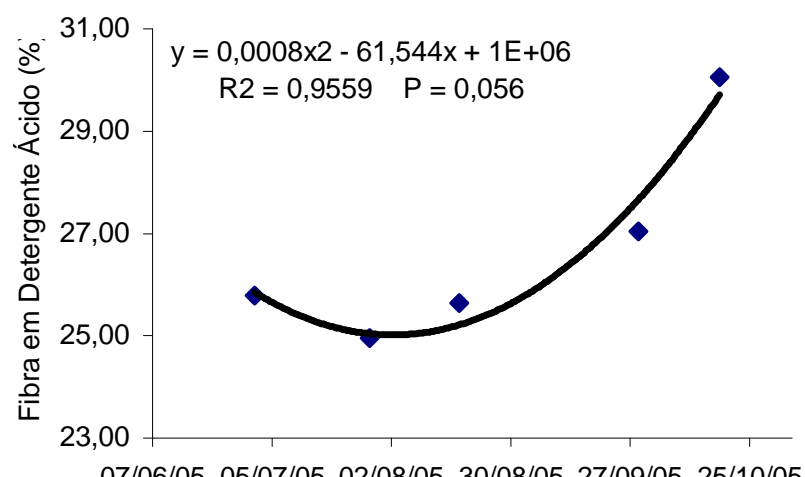

Periodo Experimental

Figura 2 - Valores médios de proteína bruta (\%) (A) e fibra em detergente ácido (\%) (B) da pastagem de aveia preta e azevém ao longo do período experimental.

Entre as alturas de pastejo não foi verificado diferença para os valores médios de FDA $\left(y=-0,0179 x^{2}+0,6321 x+\right.$ 22,$\left.125 ; R^{2}=0,8339 ; P=0,1648\right)$ e FDN (y $=-0,0153 x^{2}+0,5786 x+55,75 ; R^{2}=$ $0,3086 ; P=0,399)$. Esse resultado vai de encontro ao obtido por outros autores em pastagens temperadas manejadas sob diferentes ofertas de forragem (Gazda et al., 2004; Piazzetta et al., 2004).

Os valores de FDA e FDN obtidos nesse trabalho são próximos aos $25,6 \%$ e $58,6 \%$, respectivamente, encontrados por Freitas et al. (2003) em pastagem de azevém.

Entre as coletas observou-se que os valores de proteína bruta foram superiores na primeira avaliação, tendendo a diminuir com o decorrer do período avaliado. Resultado inverso foi obtido para FDA, que apresentou níveis significativamente maiores no último período (Figura 2).

Segundo Rocha et al. (2007a) o teor de PB na entrada dos animais na pastagem reflete a qualidade da forragem colhida no primeiro dia de pastejo. Como o comportamento se torna mais seletivo à medida que aumenta o número de dias dos animais no piquete, gradualmente a qualidade diminui, o que explica a diferença da qualidade de forragem da entrada e saída dos animais da pastagem.

A redução na qualidade bromatológica da forragem também pode ser explicada pela redução da proporção de folhas, aumento de colmos e material morto, e pela lignificação das paredes celulares nos ao longo do desenvolvimento do ciclo das forrageiras (Rocha et al. 2007b).

\section{CONCLUSÕES}

A utilização de gramíneas temperadas como aveia preta e azevém, proporcionou forragem de excelente qualidade na região Centro-ocidental do Estado do Paraná, o que comprova o potencial de utilização destas plantas para incrementar a produtividade nas propriedades agropecuárias da região.

\section{REFERÊNCIAS}

AOAC-ASSOCIATION OF OFFICIAL ANALYTICAL CHEMISTS. Official Methods of Analysis of the Association of Official Analytical Chemists. 16. ed. Washington, D.C.: AOAC, 1997.

BARBOSA, C. M. P.; CARVALHO, P. C. F.; CAUDURO, G. F.; LUNARDI, R.; KUNRATH, T. R.; GIANLUPPI, G. D. F. Terminação de cordeiros em pastagens de azevém anual manejadas em diferentes intensidades e métodos de pastejo. Revista Brasileira de Zootecnia, v.36, n.6, p.1953-1960, 2007.

BARTHRAM, G.T. Experimental techniques: the HFRO sward stick. In: Hill Farming Reaserch Organisation Biennial Report 1984. 1985. HFRO, p.29-30, 1986.

BONA FILHO, A,; MARTINICHEN, D. Produção de bovinos de corte na integração lavoura $X$ pecuária. In: I Encontro de Integração Lavoura-Pecuária no 
Sul do Brasil, 1, 2002, Pato Branco. Anais... Pato Branco: CEFET-PR, p. 133-148. 2002.

CECATO, U.; SARTI, L.L.; SAKAGUTI, E.S.; DAMASCENO, J.C. Avaliação de cultivares e linhagens de aveia (Avena spp). Acta Scientiarum, v.20, n.3, p.347-354, 1998.

FERREIRA, D. F. Programa de análises estatísticas (Statistical AnalysisSoftware) e planejamento de experimentos. Universidade Federal de Lavras, 2003.

FREITAS, F. K.; ROCHA, M. G.; PIRES, C. C.. Características qualitativas da pastagem de azevém submetida a três alturas de pastejo. In: REUNIÃO ANUAL DA SOCIEDADE BRASILEIRA DE ZOOTECNIA, 40, 2003, Santa Maria.

Anais...Santa Maria: SBZ, 2003, CD-rom.

GAZDA, T. L.; PIAZZETTA, R. G.; MONTEIRO, A. L. G.; DITTRICH, J.R. Características qualitativas de Lolium multiflorum LAM submetida a duas pressões de pastejo. In: II Symposium on Grassland Ecophysiology and Grazingecology, 2004, Curitiba - PR. Anais... Curitiba: UFPR, 2004. Cd-rom.

GOES, R.H.T.B.; MANCIO, A.B.; LANA, R.P. Avaliação da pastagem de capim Tanner-Grass (Brachiaria arrecta), por três diferentes métodos de amostragem. Revista Brasileira de Zootecnia, v.32, n.1, p.64-69, 2003.

JOHNSON, A.D. Sample preparation and chemical analysis of vegetation. In: MANETJE, L. t' (Ed.) Measurement of grassland vegetation and animal production. Aberustwyth: Commonwealth Agricultural Bureaux, 1978. p.96-102.

MACARI, S.; ROCHA, M. G.; RESTLE, J.; PILAU, A.; FREITAS, F. K.; NEVES, F. P. Avaliação da mistura de cultivares de aveia preta (Avena strigosa Schreb) com azevém (Lolium multiflorum Lam.) sob pastejo. Ciência Rural. v.36, n.3, p.910-915, 2006.

MORAES, C.H.B.K.; PAULINO, M.F.;

ZERVOUDAKIS, J.T. Avaliação qualitativa da pastagem diferida de Brachiaria decumbens stapf., sob pastejo, no período da seca, por intermédio de três métodos de amostragem. Revista Brasileira de Zootecnia. v.34, n.1, p.30-35, 2005.
MORENO, J. A. Clima do Rio Grande do Sul. Porto Alegre: Secretaria da Agricultura, 1961. 41p.

MOTT, G.E.; LUCAS, H. L. The design, conduct en interpretation of grazing trials on cultivated and improved pastures. INTERNATIONAL GRASSLAND CONGRESS, 1952. Proceedings.... IGC, 1952. p.1380.

NATIONAL RESEARCH COUNCIL - NRC. Nutrient requirement of beef cattle. 6.ed. Washington, D.C.: National Academy Press, 1984. 90p.

PIAZZETTA, R. G.; GAZDA, T. L.; MONTEIRO, A. L. G.; DITTRICH, J.R. Características qualitativas de aveia preta (avena strigosa schreb.) submetida a duas pressões de pastejo. In: II Symposium on Grassland Ecophysiology and Grazingecology, 2004, Curitiba - PR. Anais... Curitiba: UFPR, 2004. Cd-rom.

ROCHA, M. G.; PEREIRA, L. E. I. T.; SCARAVELLI, L. F. B.; OLIVO, C. J.; AGNOLIN, C. A.; ZIECH, M. F. Produção e qualidade de forragem da mistura de aveia e azevém sob dois métodos de estabelecimento. Revista Brasileira de Zootecnia, v.36, n.1, p.7-15, 2007a.

ROCHA, M. G.; QUADROS, F. L. F.; GLIENKE, C. L.; CONFORTIN, A. C. C.; COSTA, V. G.; ROSSI, G. E. Avaliação de espécies forrageiras de inverno na Depressão Central do Rio Grande do Sul.

Revista Brasileira de Zootecnia, v.36, n.6, p.1990-1999, 2007b.

ROSO, C.; RESTLE, J. Aveia preta, triticale e centeio em mistura com azevém. 2. Produtividade animal e retorno econômico. Revista Brasileira de Zootecnia, v.29, n.1, p.85-93, 2000.

ROSO, C.; RESTLE, J.; SOARES, A. B.; ANDREATTA, E. Aveia preta, triticale e centeio em mistura com azevém. 1. Dinâmica, produção e qualidade de forragem. Revista Brasileira de Zootecnia., v.29, n.1, p.75-84, 2000.

VAN SOEST, P. J., ROBERTSON, J. B., LEWIS, B. A. Symposium: carbohydrate methodology, metabolism, and nutritional implications in dairy cattle. Journal Dairy Science. v.74, n. 10, p. 35833597, 1991. 